\title{
Functional status, heart rate, and rhythm abnormalities in 521 Fontan patients 6 to 18 years of age
}

\author{
Andrew D. Blaufox, MD, ${ }^{a}$ Lynn A. Sleeper, ScD, ${ }^{b}$ David J. Bradley, MD, ${ }^{c}$ Roger E. Breitbart, MD, ${ }^{d}$ Allan Hordof, MD,
} Ronald J. Kanter, MD, ${ }^{f}$ Elizabeth A. Stephenson, MD, ${ }^{9}$ Mario Stylianou, PhD, ${ }^{\text {h }}$ Victoria L. Vetter, MD, and J. Philip Saul, MD, ${ }^{a}$ for the Pediatric Heart Network Investigators

Supplemental material is available online.

From the Medical University of South Carolina, Charleston, $\mathrm{SC}^{\mathrm{a}}$; New England Research Institutes, Watertown, Mass ${ }^{\text {b }}$; University of Utah, Primary Children's Medical Center, Salt Lake City, Utah'; Children's Hospital Boston and Harvard Medical School, Boston, Mass ${ }^{\mathrm{d}}$; Children's Hospital of New York, Columbia University, New York, $\mathrm{NY}^{\mathrm{e}}$; Duke University School of Medicine, Durham, NC; ; The Hospital for Sick Children, Toronto, Ontario, Canada ${ }^{\mathrm{g}}$; National Heart, Lung, and Blood Institute, Bethesda, $\mathrm{Md}^{\mathrm{h}}$; and Children's Hospital of Philadelphia, Philadelphia, $\mathrm{Pa}^{\mathrm{i}}$.

This work was supported by grants U01 HL068281, U01 HL068270, U01 HL068292, U01 HL068285, U01 HL068290, U01 HL068269, U01 HL068288, and U01 HL068279 from National Heart, Lung, and Blood Institute, National Institutes of Health, Department of Health and Human Services.

Received for publication Sept 14, 2007; revisions received Nov 29, 2007; accepted for publication Dec 18, 2007

Address for reprints: Andrew D. Blaufox, MD, Children's Heart Center, Schneider Children's Hospital, 269-01 176th Ave, New Hyde Park, NY 11040 (E-mail: Ablaufox@nshs.edu).

J Thorac Cardiovasc Surg 2008;136:100-7 0022-5223/\$34.00

Copyright $\odot 2008$ by The American Association for Thoracic Surgery

doi:10.1016/j.jtcvs.2007.12.024
Objectives: Our objective was to determine the relationship between functional outcome and abnormalities of heart rate and rhythm after the Fontan operation.

Methods: The National Heart, Lung, and Blood Institute Pediatric Heart Network conducted a cross-sectional analysis of patients who had undergone a Fontan procedure at the 7 network centers. Analysis was based on 521 patients with an electrocardiogram $(\mathrm{n}=509)$ and/or bicycle exercise test $(\mathrm{n}=404)$. The Child Health Questionnaire parent report and the oxygen consumption at the anaerobic threshold were used as markers of functional outcome.

Results: Various Fontan procedures had been performed: intracardiac lateral tunnel (59\%), atriopulmonary connection (14\%), extracardiac later tunnel (13\%), and extracardiac conduit (11\%). Prior volume unloading surgery was performed in 389 patients: bidirectional Glenn $(70 \%)$ and hemi-Fontan $(26 \%)$. A history of atrial tachycardia was noted in $9.6 \%$ of patients and $13.1 \%$ of patients had a pacemaker. Lower resting heart rate and higher peak heart rate were each weakly associated with better functional status, as defined by higher anaerobic threshold $(R=-0.18, P=.004$, and $R=0.16$, $P=.007$, respectively) and higher Child Health scores for physical functioning $(R=$ $-0.18, P<.001$, and $R=0.17, P=.002$, respectively). Higher anaerobic threshold was also independently associated with younger age and an abnormal P-axis. Resting bradycardia was not associated with anaerobic threshold or Child Health scores.

Conclusions: In pediatric patients (6-18 years) after the Fontan procedure, a lower resting heart rate and a higher peak heart rate are each independently associated with better physical function as measured by anaerobic threshold and Child Health scores. However, these correlations are weak, suggesting that other, nonrhythm and nonrate, factors may have a greater impact on the functional outcome of pediatric patients after the Fontan operation.

$\mathrm{H}$ eart rate and rhythm disorders, such as sinus node dysfunction and atrial tachycardia, are common and potentially important late morbidities of the Fontan operation. ${ }^{1-10}$ The incidence of late sinus node dysfunction after the Fontan operation has been reported to be about $15 \%{ }^{1-3}$ but may occur in up to $44 \%$ of patients in selected series. ${ }^{4}$ The incidence of atrial tachycardia is $16 \%$ to $17 \%$ at approximately 5 years after the Fontan procedure ${ }^{1,5}$ and reaches $50 \%$ by 12 years. ${ }^{1}$ Further, sinus node dysfunction and atrial tachycardia can result in significant symptoms and comorbidities necessitating interventions, including medication, ${ }^{11}$ pacing, ${ }^{12}$ catheter ablation, ${ }^{13}$ and surgery, ${ }^{14}$ and may also be associated with an increased risk for late death. ${ }^{7,12,15,16}$ However, little is known about the impact of heart rate and rhythm disorders on the daily lives of pediatric patients who have undergone the Fontan operation.

The goal of this study was to analyze heart rate and rhythm data from a large group of Fontan patients studied with a uniform protocol to define the incidence of heart rate 


\section{Abbreviations and Acronyms \\ ECG = electrocardiogram \\ CHQ = Child Health Questionnaire \\ CHQ-PF50 = Child Health Questionnaire Parent Report \\ CHQ-p = Child Health Questionnaire-physical \\ CHQ-ps = Child Health Questionnaire-psychosocial \\ VAT $=$ oxygen consumption at anaerobic threshold}

and rhythm abnormalities in this patient population and to determine the impact of these abnormalities on quantifiable measures of functional outcome.

\section{Methods}

\section{Fontan Cross-Sectional Study}

This report is based on data from the Fontan Cross-Sectional Study executed by the Pediatric Heart Disease Clinical Research Network of the National Heart, Lung, and Blood Institute. The primary aim of this main study was to assess the correlation between functional health status and measures of ventricular performance in children aged 6 to 18 years who have undergone a Fontan procedure. Details regarding the structure of the Pediatric Heart Network and the general methods of the Fontan CrossSectional Study have been reported previously. ${ }^{17}$ Informed consent was obtained and data were collected at each of the participating centers according to the rules of each institution's internal review board.

Heart rate, heart rhythm, and functional analysis-Patient sample. A total of 546 subjects were enrolled in the Fontan Cross-Sectional Study. Twenty-five patients were excluded from this analysis of heart rate and rhythm: In 17, neither an electrocardiogram (ECG) nor an exercise test was available; 7 had undergone surgical conversion of the Fontan circuit, which may have had an impact on arrhythmia development ${ }^{14}$; and 1 had seconddegree atrioventricular block, leaving 521 subjects in the analytic data set.

Some additional exclusions were applied for selected heart rate and rhythm analyses. Patients with a pacemaker may have had a falsely elevated heart rate at rest and during exercise, whereas patients receivinging antiarrhythmic drugs may have had a falsely lowered heart rate. Thus the physiologic relationship between underlying heart rate and outcome in these patients might not be accurately identified. To avoid this possibility, we excluded from all heart rate analyses 34 subjects with a rate-responsive pacemaker $(\mathrm{n}=5)$ and/or subjects who were currently treated with betablockers or class III antiarrhythmics $(n=30)$, and we excluded 43 subjects with a paced rhythm on resting ECG from the resting heart rate analysis.

Functional outcome measures. The Child Health Questionnaire (CHQ) Parent Report (CHQ-PF50) and the oxygen consumption (volume $\mathrm{O}_{2} \cdot \mathrm{kg}^{-1} \cdot \mathrm{min}^{-1}$ ) at the anaerobic threshold (VAT) during exercise testing were used as measures of functional outcome. The CHQ-PF50 provides physical (CHQ-p) and psychosocial (CHQ-ps) summary scores to describe the well-being of children 5 to 18 years of age. ${ }^{18}$ This instrument has been used extensively to establish functional outcome in normal children as well as pediatric patients with various diseases and is among the most reliable tools for this purpose. ${ }^{19}$ For this study, VAT was used as the marker for exercise performance because it is less effort dependent than other measures and reflects performance at lower levels of exercise.

ECG. A standard 12-lead ECG was performed in the supine position and recorded at $25-\mathrm{mm} / \mathrm{s}$ sweep speed with a $10 \mathrm{~mm} /$ $\mathrm{mV}$-amplitude. All ECGs were performed at supine rest and before any exercise testing. Bradycardia was defined as a resting heart rate less than the fifth percentile for age. ${ }^{20}$

Exercise testing. A 12-lead ECG was continuously monitored during the exercise protocol. Arterial oxygen saturation was measured transcutaneously at rest and continuously during exercise. Maximal exercise testing was performed with a standard ramp protocol on an electronically braked cycle ergometer. ${ }^{21}$

Oxygen consumption and carbon dioxide production were measured continuously. VAT was measured by the V-slope method in those children in whom it could be accurately determined.

Peak heart rate percent predicted of normal for age was calculated as (peak heart rate/[220 - age]) $\times 100$. Chronotropic index ${ }^{22}$ was calculated as (peak heart rate - resting heart rate) $/(0.925 \times$ [220 - age - resting heart rate]).

\section{Statistical Analysis}

Groups were defined by resting heart rate less than fifth percentile, peak heart rate less than $75 \%$ of predicted for age, history versus no history of atrial tachycardia, and current versus no pacemaker use. A Fisher exact test was used when comparing the distributions of a categorical variable by group and the Wilcoxon rank sum test was used for comparison of the distribution of most continuous variables. The Student $t$ test was used to compare the distributions of resting heart rate. The Pearson rank correlation coefficient was used to estimate the association between pairs of continuous measures. Multivariate linear regression was used to identify independent predictors of functional outcome, defined as VAT and CHQ-p (physical) summary score.

\section{Results}

\section{Enrollment, Demographics, and History}

Of the 521 subjects in the analytic cohort, 509 had a supine ECG, 404 completed a bicycle exercise test with VAT measured in 311, and 489 had analyzable CHQ-p summary scores.

Table 1 displays patient demographics. The mean age at enrollment was $11.9 \pm 3.4$ years (median 11.3) and at the Fontan procedure was $3.4 \pm 1.9$ years (median 2.8 ). There were more male $(61 \%)$ than female patients. Of 389 patients who had undergone a staged second procedure, many more $(70 \%)$ underwent the bidirectional Glenn than the hemi-Fontan. The intracardiac lateral tunnel was the most frequent form of Fontan procedure seen in these patients (59\%), with the 3 other major forms being equally distributed among the remainder of the patients. Sixty-eight (13\%) patients had a pacemaker at the time of the study. Fifty (10\%) patients had a history of atrial tachycardia, defined as atrial tachycardia noted in the medical record or present on the study ECG or exercise test. 
TABLE 1. Fontan cross-sectional study patient characteristics for 521 subjects with an ECG or undergoing an exercise test

\begin{tabular}{lcc}
\hline \multicolumn{1}{c}{ Characteristic } & n & Result \\
\hline Age at enrollment, y (median) & 521 & $11.9 \pm 3.4(11.3)$ \\
Age at Fontan procedure, & 521 & $3.4 \pm 1.9(2.8)$ \\
$\quad$ y (median) & 521 & $315(60.5 \%)$ \\
Male & 519 & \\
Race & & $411(79.2 \%)$ \\
$\quad$ White & & $55(10.6 \%)$ \\
African American & $14(2.7 \%)$ \\
Asian & & $39(7.5 \%)$ \\
Other & 389 & \\
Type of volume unloading & & $272(69.9 \%)$ \\
$\quad$ operation & & $101(26.0 \%)$ \\
Bidirectional Glenn & $16(4.1 \%)$ \\
Hemi-Fontan & & $72(13.8 \%)$ \\
Other & 521 & $307(58.9 \%)$ \\
Fontan type & & $62(11 . \%)$ \\
Atriopulmonary connection & & $69(13.2 \%)$ \\
Intracardiac lateral tunnel & & $11(2.1 \%)$ \\
Extracardiac lateral tunnel & & $68(13.1 \%)$ \\
Extracardiac conduit & & $50(9.6 \%)$ \\
Other & & \\
Current pacemaker & & \\
History of atrial tachycardia & 521 &
\end{tabular}

ECG, Electrocardiogram.

\section{Heart Rate and Rhythm}

Resting rhythm. Sinus rhythm was the predominant rhythm on the resting supine ECG in only $69 \%$ of patients (Figure 1). Among 470 patients with a $\mathrm{P}$ wave on the ECG, $20 \%$ had a low right atrial rhythm and $5 \%$ had a left atrial focus. Although $13 \%$ of patients had a pacemaker, during the resting supine ECG, only $63 \%$ of these were paced in the following modes: $\mathrm{AAI}(\mathrm{R})(69 \%), \mathrm{DDD}(\mathrm{R})(28 \%)$, or DDIR (3\%).

Resting heart rate. After appropriate exclusions (see Methods), the average resting heart rate on ECG was $76 \pm$ 16 beats/min. Resting heart rate decreased slightly with age $(R=-0.15,95 \%$ confidence interval -0.24 to $-0.06 ; P$ $=.001)$. Over one quarter $(27 \%)$ of patients had a resting heart rate below the fifth percentile for age, but only $0.7 \%$ had resting heart rates above the 95th percentile for age. Patients with resting heart rates less than the fifth percentile for age were less likely to be in sinus rhythm and more likely to be in junctional escape rhythm than those patients with resting heart rates greater than the fifth percentile for age (67\% vs $79 \%$ in normal sinus rhythm and $16 \%$ vs $3 \%$ in junctional rhythm, respectively; $P<.0001$ ).

Peak heart rate. The average peak heart rate during exercise testing in 371 patients was $157 \pm 21$ beats/min and was not associated with age $(R=0.07,95 \%$ confidence interval -0.04 to $0.17 ; P=.211)$. Low peak heart rate, defined as

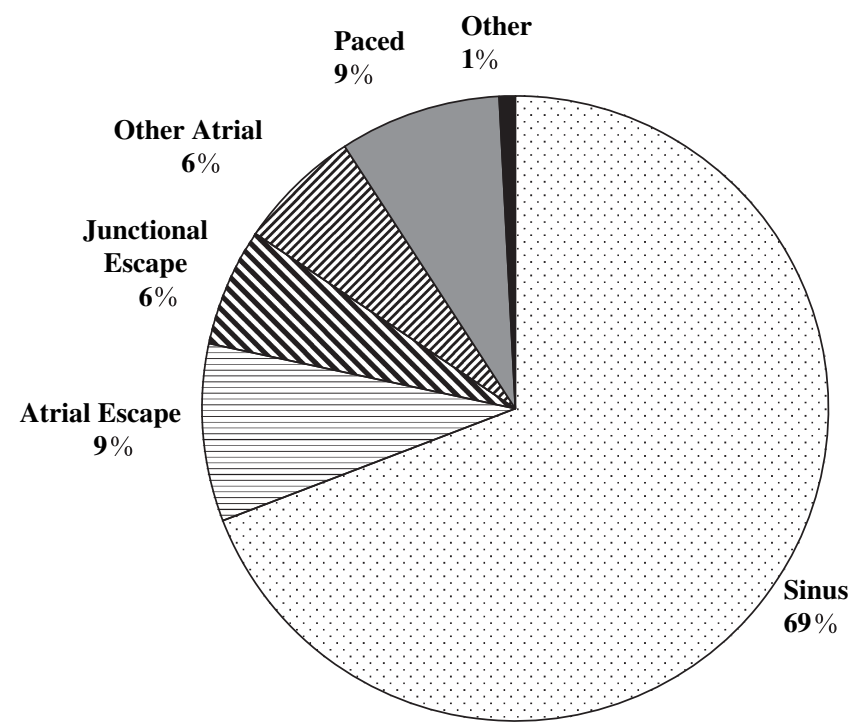

Figure 1. Predominant rhythm on resting ECG in 509 survivors of the Fontan procedure aged $12 \pm 3$ years.

less than $75 \%$ of predicted for age, was observed in $41 \%$ of patients. Mean change in heart rate (peak minus resting) was $83 \pm 26$ beats $/ \mathrm{min}$, and the mean chronotropic index $(\mathrm{n}=340)$ was $0.67 \pm 0.19$ (median 0.70 ), with $73 \%$ having an abnormally low chronotropic index less than 0.8 .

Multiple heart rate and rhythm abnormalities. Many subjects had multiple heart rate and rhythm abnormalities. Nine percent had a resting heart rate below the fifth percentile for age and nonsinus rhythm on resting ECG, and $10.9 \%$ had a resting heart rate below the fifth percentile for age plus a peak heart rate below $75 \%$ of predicted. However, $61 \%$ of the 96 patients who had a resting heart rate below the fifth percentile for age had a peak heart rate $75 \%$ of predicted or greater.

\section{Functional Outcomes}

Mean CHQ-p and CHQ-ps for the group were lower than those for historical healthy controls: CHQ-p was $45.4 \pm$ 11.8 (median 49.3) versus $53.0 \pm 8.8$ for historical controls and CHQ-ps was $47.3 \pm 10.9$ (median 48.9) versus $51.2 \pm$ 9.1 for historical controls. ${ }^{18,19}$ Mean VAT was low at 18.8 $\pm 6.4 \mathrm{~mL} \cdot \mathrm{kg}^{-1} \cdot \mathrm{min}^{-1}$.

\section{Associations with Oxygen Consumption at the Anaerobic Threshold (VAT)}

VAT was measured in 311 subjects. Higher VAT was weakly associated with lower resting heart rate $(R=-0.18,95 \%$ confidence interval -0.27 to $-0.09 ; P=.004$; Figure 2, $A)$ and higher peak heart rate $(R=0.16,95 \%$ confidence interval 0.04 to $0.27 ; P=.07$; Figure $3, A$ ). When the 

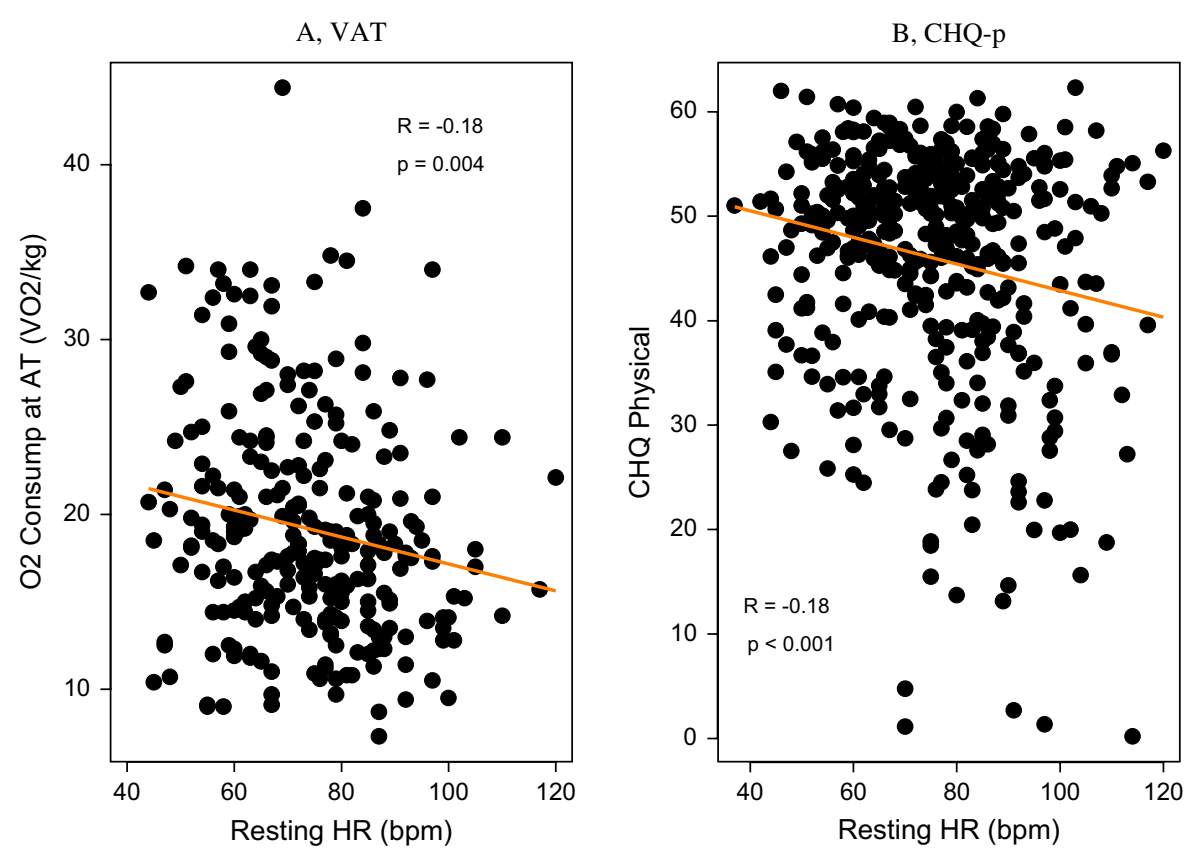

Figure 2. Resting heart rate and functional outcome in survivors of the Fontan procedure. AT, Anaerobic threshold; CHO Physical, Child Health Questionnaire (Parent Report) Physical Summary score; $\mathrm{VO}_{2}$, oxygen consumption; $H R$, heart rate.

association between continuous predicted peak heart rate and VAT was examined, the strength and significance of the association was similar to the association between raw peak heart rate and VAT.

VAT was not associated with bradycardia (resting heart rate below the fifth percentile for age) or the presence of an atrial pacemaker (Table 2). Although patients with an abnormal P-axis had a higher VAT than those with a normal axis $\left(20.7 \pm 6.8\right.$ vs $\left.18.4 \pm 6.2 \mathrm{~mL} \cdot \mathrm{kg}^{-1} \cdot \min ^{-1} ; P=.02\right)$, VAT did not differ by predominant rhythm, including junctional rhythm, on resting ECG. VAT did not differ by history of atrial tachycardia status or by the use of antiarrhythmic medication. A multivariate model for VAT $(n=251)$ using age, rate, and rhythm variables demonstrated that younger age $\left(0.77 \mathrm{~mL} \cdot \mathrm{kg}^{-1} \cdot \mathrm{min}^{-1}\right.$ increase per 1 -year decrease in age; $P<.001)$, lower resting heart rate $\left(0.91 \mathrm{~mL} \cdot \mathrm{kg}^{-1}\right.$ - $\min ^{-1}$ increase per 10 beats/min decrease at rest; $P<$ $.001)$, higher peak heart rate $\left(0.44 \mathrm{~mL} \cdot \mathrm{kg}^{-1} \cdot \mathrm{min}^{-1}\right.$ increase per 10 beats/min increase during exercise; $P=$ $.03)$, and an abnormal P-axis $\left(2.59 \mathrm{~mL} \cdot \mathrm{kg}^{-1} \cdot \mathrm{min}^{-1}\right.$ decrease if $\mathrm{P}$-axis is between 0 and 90 degrees; $P=.004$ ) were independent predictors of better performance and accounted for $20 \%$ of the variation in VAT. Furthermore, the association between age and resting and peak heart rate was observed at all ages, without a difference between age groups (interaction $P$ values .77 and 0.41 , respectively).

\section{Associations with CHQ-p Score}

Patients with lower resting heart rates had higher CHQ-p scores, reflecting better functional outcome $(R=-0.18$,
95\% confidence interval -0.27 to $0.09 ; P<.001$; Figure 2 , $B)$. However, bradycardia was not specifically related to CHQ-p, since mean CHQ-p was similar for patients with a resting heart rate at or above versus below the fifth percentile for age (Table 2). Patients with a higher peak heart rate had higher CHQ-p scores $(R=0.17,95 \%$ confidence interval 0.06 to $0.27 ; P=.002$; Figure $3, B$ ). When the association between continuous predicted peak heart rate and CHQ-p score was examined, the strength and significance of the association was similar to the association between raw peak heart rate and CHQ-p score. Greater changes in heart rate (peak heart rate minus resting heart rate) were associated with higher CHQ-p scores $(R=0.19,95 \%$ confidence interval 0.08 to $0.29 ; P<.001)$. The presence of an atrial pacemaker was associated with a lower mean CHQ-p score, as was a positive history of atrial tachycardia (Table 2). Patients who were treated with beta-blockers or class III antiarrhythmic agents had lower CHQ-p scores than those who were not treated with these medications $(38.3 \pm 15.9$ vs $45.9 \pm 11.3$; $P=.005)$. Other than having a paced rhythm on resting ECG, predominant rhythm, including junctional rhythm, was not associated with a lower CHQ-p. A multivariate model for CHQ-p score $(n=324)$ using age and rate and rhythm variables demonstrated that resting heart rate (8.1point increase in CHQ-p score per 10 beats/min decrease at rest; $P=.02)$ and peak heart rate $(7.0$-point increase in CHQ-p score per 10 beats/min increase during exercise; $P=.01)$ were both independent predictors of CHQ-p. However, these variables accounted for only $4 \%$ of the variation in CHQ-p scores. Age, predominant rhythm, a history of atrial tachycardia, the presence of a pacemaker, and the change 

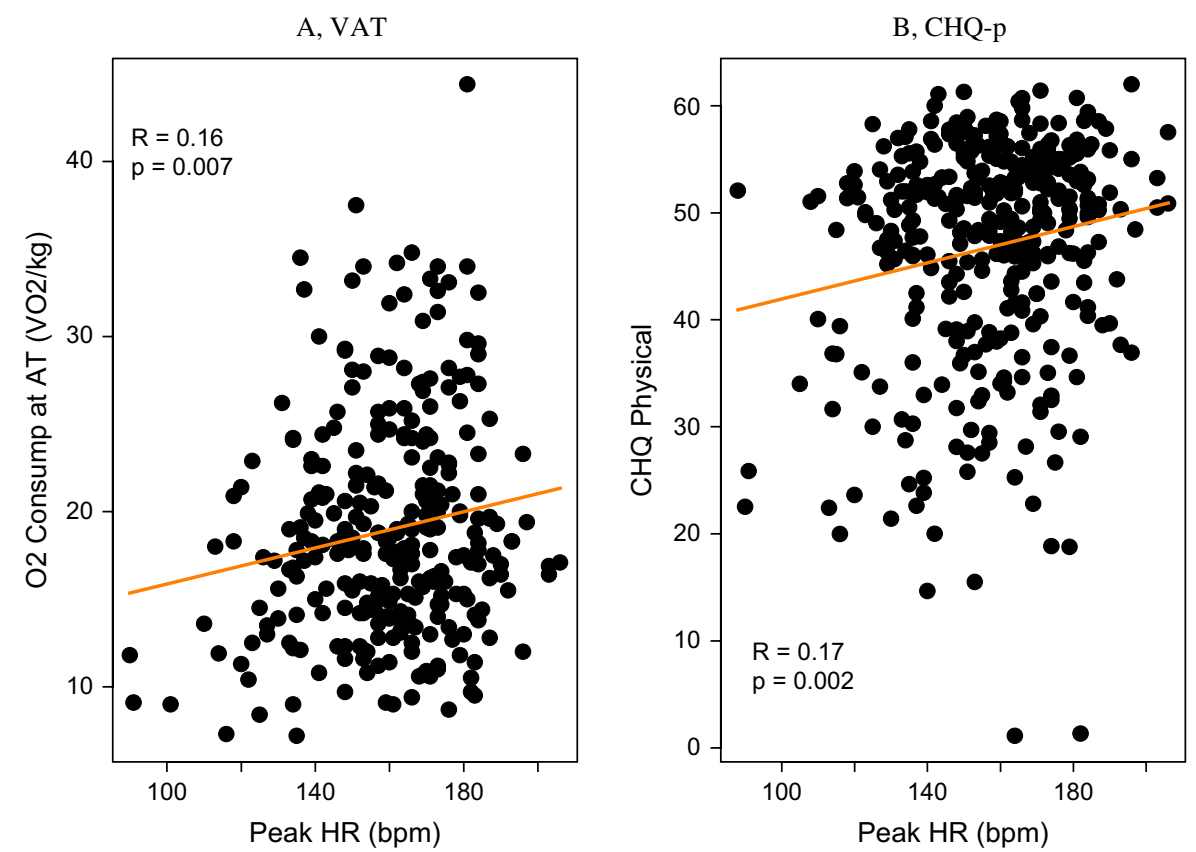

Figure 3. Peak heart rate and functional outcome in survivors of the Fontan procedure. AT, Anaerobic threshold; $\mathrm{CHO}$ Physical, Child Health Questionnaire (Parent Report) Physical Summary score; $\mathrm{VO}_{2}$, oxygen consumption; $\mathrm{HR}$, heart rate.

from resting to peak heart rate were not independently associated with CHQ-p after accounting for resting and peak heart rate.

\section{Associations with CHQ-ps Score}

None of the heart rate and rhythm variables were associated with CHQ-ps.

\section{Discussion}

This study provided a unique opportunity to analyze the associations of heart rate and rhythm with functional outcome in a large group of patients who had undergone the Fontan operation at 7 centers during a relatively uniform surgical era. The study offers new insight into the potential impact of these factors on the daily lives of Fontan patients. The specific new findings in this study are as follows: (1) resting heart rate as a continuous measure was inversely related to functional outcome measured by VAT and CHQ-p; (2) bradycardia (resting heart rate $<$ fifth percentile for age) was not related to poor functional outcome; and (3) although lower than normal, peak heart rate during exercise was positively correlated with both VAT and CHQ-p. Additionally, this large sample, with its well-defined criteria for heart rate and rhythm abnormalities, provides a more accurate description of the prevalence of rate and rhythm abnormalities in patients who have undergone the Fontan procedure than has been previously available.

\section{Heart Rate and Functional Outcome}

The most intriguing finding in this study is that, independent of age, lower resting heart rate was not associated with wors- ened functional outcome. Since heart rate normally falls with age and outcome usually worsens with age, the relationship between resting heart rate and outcome should be even stronger if age-adjusted heart rates were available for use or could be accurately derived from existing data. Further, despite a large number of patients with bradycardia, defined as a resting heart rate less than the fifth percentile for age, bradycardia was not associated with decreased functional status. On the surface, this finding appears to be at odds with previous studies that have associated sinus node dysfunction with lower physical performance. Sinus node dysfunction has often been broadly defined as various combinations of the following: nonsinus rhythm on resting ECG, low resting heart rate, low peak heart rate response to exercise, or long pauses. ${ }^{1-12,15,16,23,24}$ However, these prior studies have typically not separately analyzed the individual components of sinus node dysfunction, perhaps accounting for the differences with the findings in the present study.

One possible explanation for the association between resting heart rate and functional outcome is that a high resting heart rate is an indicator of a poor functional state, perhaps resulting from low cardiac output and reflex sympathetic stimulation. Conversely, we speculate that a low resting heart rate may confer mechanical advantages to the Fontan ventricle. This may be related to longer diastolic filling times supporting the preload dependency of the Fontan circulation or to improvement in load-independent diastolic mechanics. Of note, very few patients had a resting heart rate above the 95th percentile for age. The data in this study do not address whether a low resting heart rate is part of a compensatory mechanism; however, previous authors have proposed 
TABLE 2. Heart rate and rhythm associations with oxygen consumption at the anaerobic threshold (VAT) and Parent Report Child Health Questionnaire Physical Summary Score (CH0-p)

\begin{tabular}{|c|c|c|c|c|}
\hline & $\mathbf{n}$ & VAT $\left(\mathrm{mL} \cdot \mathrm{kg}^{-1} \cdot \min ^{-1}\right)$ & $\mathbf{n}$ & СНО-р \\
\hline \multicolumn{5}{|l|}{ Resting heart rate } \\
\hline$<5$ th percentile for age & 75 & $20.1 \pm 6.9$ (median 19.2) & 117 & $48.1 \pm 8.4($ median 50.0$)$ \\
\hline$\geq 5$ th percentile for age & 185 & $18.8 \pm 6.3($ median 17.6$)$ & 302 & $45.2 \pm 12.0$ (median 48.7) \\
\hline$P$ & & .137 & & .154 \\
\hline \multicolumn{5}{|l|}{ Peak heart rate } \\
\hline$<75 \%$ of predicted for age & 98 & $18.5 \pm 6.2($ median 18.0$)$ & 142 & $45.3 \pm 11.3($ median 18.0$)$ \\
\hline$\geq 75 \%$ of predicted for age & 191 & $19.2 \pm 6.4($ median 17.9$)$ & 210 & $47.8 \pm 9.7$ (median 50.3) \\
\hline$P$ & & .539 & & .082 \\
\hline Current pacemaker & 41 & $18.1 \pm 5.9($ median 17.0$)$ & 61 & $40.8 \pm 14.1($ median 45.0$)$ \\
\hline No current pacemaker & 270 & $18.9 \pm 6.5($ median 18.1$)$ & 428 & $46.0 \pm 11.3($ median 49.5$)$ \\
\hline$P$ & & .509 & & .007 \\
\hline History of AT & 30 & $17.2 \pm 6.7($ median 15.7$)$ & 45 & $38.8 \pm 15.0$ (median 45.2) \\
\hline No history of AT & 281 & $19.0 \pm 6.4($ median 18.1$)$ & 444 & $46.0 \pm 11.3$ (median 49.8) \\
\hline$P$ & & .081 & & .0008 \\
\hline Abnormal P-axis & 64 & $20.7 \pm 6.8($ median 19.1$)$ & 110 & $43.3 \pm 12.7$ (median 46.4) \\
\hline Normal P-axis & 214 & $18.4 \pm 6.2($ median 17.4$)$ & 334 & $46.0 \pm 11.1$ (median 49.6) \\
\hline$P$ & & .015 & & .071 \\
\hline Nonsinus rhythm & 89 & $19.8 \pm 6.5($ median 18.0$)$ & 146 & $44.1 \pm 12.9($ median 48.2$)$ \\
\hline Sinus rhythm & 210 & $18.6 \pm 6.4($ median 17.8$)$ & 333 & $45.7 \pm 11.3($ median 49.5$)$ \\
\hline$P$ & & .183 & & .394 \\
\hline
\end{tabular}

$A T$, Atrial tachycardia.

that resting bradycardia in Fontan patients may be more likely to be the result of surgical or functional autonomic derangements, with selective reduction of cardiac sympathetic activation rather than sinus node dysfunction. ${ }^{25}$ Any link between autonomic function and the association between higher CHQ-p score and lower heart rate will need to be substantiated in further studies.

The role of peak heart rate in these patients may be more complex. It is clear that the population had an abnormal heart rate response to exercise, with $73 \%$ of subjects having an abnormally low chronotropic index. The chronotropic index may be a better representation of the expected peak heart rate response to exercise than the formula (peak heart rate $=220$ - age [years]). ${ }^{22}$ It is less clear whether the abnormal chronotropy is due to intrinsic sinus node dysfunction, autonomic derangements, or other mechanisms. Regardless of the etiology, a higher peak heart rate was associated with a higher VAT and a higher CHQ-p. Although this relationship was found to be weak in this group of Fontan patients, its existence is no different from that in patients with normal hearts, ${ }^{26}$ in whom increasing heart rate is the most important mechanism for augmenting cardiac output during exercise.

Although other studies have demonstrated that pacing is indicated in Fontan patients with symptomatic bradycardia, ${ }^{1,3,4}$ the clinical message from this study might be that good functional outcomes in patients with low resting heart rates suggests that placement of a pacemaker for asymptomatic bradycardia might not improve clinical status and may warrant very careful reconsideration. Inasmuch as a higher peak heart rate was also correlated with better functional outcome, failure to increase heart rate during exercise may be a better indicator of pacemaker necessity, but this needs to be evaluated in a prospective manner.

\section{Heart Rate and Rhythm Abnormalities}

Despite the more recent surgical era represented in the present study, the high incidence of heart rate and rhythm abnormalities in this Fontan population is consistent with that reported by previous authors. ${ }^{1-10}$ In the present study, $27 \%$ of patients had resting heart rates below the fifth percentile for age, $31 \%$ had a nonsinus rhythm on resting ECG, and $41 \%$ had a peak heart rate less than $75 \%$ of predicted. Previous studies defined sinus node dysfunction as having any one of these abnormalities, ${ }^{1-3}$ with a prevalence of up to $44 \%$ in select series. ${ }^{4}$ Fishberger and associates ${ }^{7}$ reported that $9.2 \%$ of Fontan patients had a pacemaker after a mean follow-up of 6 years, similar to the $13 \%$ prevalence during a followup of about 8.5 years in this study. Interestingly, the incidence of atrial tachycardia in the present study was lower than reported in prior studies despite a longer follow-up period $(9.6 \%$ at 8.5 years compared with $16 \%$ to $17 \%$ at 5 years). ${ }^{1,5}$ Thus the impact of the more recent era may have been greater on the development of atrial tachycardia than on other heart rate and rhythm abnormalities.

\section{Limitations}

Despite the important findings presented here, this study has several limitations. First, since the study was observational, 
causality cannot be inferred from the associations identified. Second, although this study suggests that lower resting and higher peak heart rates may be beneficial in Fontan patients, these variables accounted for only $8 \%$ of the variance in CHQ-p, indicating that other factors may be more important in determining CHQ-p than heart rate. Third, the associations found between heart rate and CHQ-p or VAT arose from a subsample of the study cohort, which excluded patients who were paced and those receiving antiarrhythmic medication. Inasmuch as the study design did not allow for the reprogramming of pacemakers so that underlying rhythm could be manifest when assessing heart rate, it is unknown whether the relationships between underlying heart rate and CHQ-p or VAT would have been different in those patients with a pacemaker. However, despite exclusion of paced patients in the heart rate analysis, a large number of patients without a pacemaker had bradycardia and were included in the analysis, indicating that the results are reasonably applicable to most Fontan patients. It is possible that the patients with pacemakers may have had more profound bradycardia than the bradycardic patients without pacemakers. Thus excluding paced patients does not necessarily negate the relationship between resting heart rate and outcome for even the paced patients. Fourth, there was not a core laboratory for the ECG or exercise testing interpretation, so that institutional variability could have influenced the results. Fifth, a definition of atrial tachycardia based on chart review, study ECG, or exercise test may have underestimated the incidence of this problem compared with methods such as 24-hour ECG monitoring and electrophysiology study. Finally, associations with VAT have to be interpreted cautiously inasmuch as only 311 patients had valid VATs reported. For subjects who underwent exercise testing, those with a VAT measurement had better physical functioning on CHQ than those without a VAT measurement. In general, the analyses of VAT as an outcome measure for Fontan subjects are based on an older and possibly somewhat healthier cohort than the other findings. Inability to reach VAT may be an important determinant of functional outcome by itself.

\section{Conclusions}

In pediatric patients (6-18 years) after the Fontan procedure, a lower resting heart rate and a higher peak heart rate during exercise are each independently associated with improved physical functional outcome as measured by the physical component of the CHQ and the VAT. However, these correlations are weak, suggesting that other, nonrhythm and nonrate, factors may have a greater impact on the functional outcome of pediatric patients undergoing the Fontan operation.

\section{References}

1. Fishberger SB, Wernovsky G, Gentles TL, Gauvreau K, Burnett J, Mayer JE, et al. Factors that influence the development of atrial flutter after the Fontan operation. J Thorac Cardiovasc Surg. 1997;113:80-6.
2. Cohen MI, Bridges ND, Gaynor J, Hoffman T, Wernovsky G, Vetter VL, et al. Modifications to the cavopulmonary anastomosis do not eliminate early sinus node dysfunction. $J$ Thorac Cardiovasc Surg. 2000;120:891-901.

3. Driscoll DJ, Offord KP, Feldt RH, Schaff HV, Puga FJ, Danielson GK. Five- to fifteen-year follow-up after Fontan operation. Circulation. 1992;85:469-96.

4. Cohen MI, Wernovsky G, Vetter VL, Wieand TS, Gaynor J, Jacobs M, et al. Sinus node function after a systematically staged Fontan procedure. Circulation. 1998;98(19 Suppl):II352-9.

5. Durongpisitkul K, Porter CJ, Cetta F, Offord KP, Slezak JM, Puga FJ, et al. Predictors of early and late-onset supraventricular tachyarrhythmias after Fontan operation. Circulation. 1998;98:1099-107.

6. Cecchin F, Johnsrude CL, Perry JC, Friedman RA. Effect of age and surgical technique on symptomatic arrhythmias after the Fontan procedure. Am J Cardiol. 1995;76:386-91.

7. Fishberger SB, Wernovsky G, Gentles TL, Gamble WJ, Gauvreau K, Burnett $\mathrm{J}$, et al. Long-term outcome in patients with pacemakers after the Fontan operation. Am J Cardiol. 1996;77:887-9.

8. Bae E, Lee J, Noh CI, Kim W, Kim Y. Sinus node dysfunction after Fontan modifications-influence of surgical method. Int J Cardiol. 2003;88: 285-91.

9. Dilawar M, Bradley SM, Saul JP, Stroud S, Balaji S. Sinus node dysfunction after intra-atrial lateral tunnel and extracardiac conduit Fontan procedures: a study of 24-hour Holter recordings. Pediatr Cardiol. 2003; 24:284-8.

10. Manning PB, Mayer JE Jr, Wernovsky G, Fishberger SB, Walsh EP. Staged operation to Fontan increases the incidence of sinoatrial node dysfunction. J Thorac Cardiovasc Surg. 1996;111:833-9.

11. Triedman JK. Atrial reentrant tachycardias. In: Walsh EP, Saul JP, Triedman JK, eds. Cardiac arrhythmias in children and young adults with conenital heart disease. Philadelphia: Lippincott Williams \& Wilkins; 2001: pp 137-60.

12. Rhodes LA, Saul JP, Gamble WJ, Walsh EP. Benefits and potential risks of atrial antitachycardia pacing after repair of congenital heart disease. $J$ Am Coll Cardiol. 1993;21:107A.

13. Triedman JK, Alexander ME, Love BA, Collins KK, Berul CI, Bevilacqua LM, et al. Influence of patient factors and ablative technologies on outcomes of radiofrequency ablation of intra-atrial reentrant tachycardia in patients with congenital heart disease. J Am Coll Cardiol. 2002;39:1827-35.

14. Mavroudis C, Backer CL, Deal BJ, Johnsrude CL. Fontan conversion to cavopulmonary connection and arrhythmia circuit cryoblation. J Thorac Cardiovasc Surg. 1998;115:547-56.

15. Gentles TL, Mayer JE, Gauvreau K, Newburger JW, Lock JE, Kupferschmid JP, et al. Fontan operation in five hundred consecutive patients: factors influencing early and late outcome.J Thorac Cardiovasc Surg. 1997;114:379-91.

16. Ghai A, Harris L, Harrison DA, Webb GD, Siu SC. Outcomes of late atrial arrhythmias in adults after the Fontan operation. $J$ Am Coll Cardiol. 2001;37:585-92.

17. McCrindle BW, Williams RV, Mitchell PD, Hsu DT, Paridon SM, Atz AM, et al. Pediatric Heart Network Investigators. Relationship of patient and medical characteristics to health status in children and adolescents after the Fontan procedure. Circulation. 2006;113: 1123-9.

18. Landgraf JM, Abetz L, Ware JE. The CHQ user's manual. 1st ed. Boston: The Health Institute, New England Medical Center. 1996.

19. Schmidt L, Garratt A, Fitzpatrick R. Child/parent-assessed population health outcome measures: a structured review. Child Care Health Dev. 2002;28:227-37.

20. Davignon A, Rautaharju P, Boiselle E, Soumis F, Megelas M, Choquette A. Normal ECG standards for infants and children. Pediatr Cardiol. 1980;21:123-31.

21. Cooper DM, Weiler-Ravell D. Gas exchange response to exercise in children. Am Rev Respir Dis. 1984;129(2 Pt 2):S47-8.

22. Diller GP, et al. Heart rate response during exercise predicts survival in adults with congenital heart disease. J Am Pediatr Cardiol. 2006; 48:1250-6. 
23. Gardiner HM, Dhillon R, Bull C, de Leval MR, Deanfield JE. Prospective study of the incidence and determinants of arrhythmia after total cavopulmonary connection. Circulation. 1996;94(9:Suppl):II17-21.

24. Gelatt M, Hamilton RM, McCrindle BW, Gow RM, Williams WG, Trusler GA, et al. Risk factors for atrial tachyarrhythmias after the Fontan operation. J Am Coll Cardiol. 1994;24:1735-41.
25. Davos CH, Francis DP, Leenarts MF, Yap SC, Li W, Davlouros PA, et al. Global impairment of cardiac autonomic nervous activity late after the Fontan operation. Circulation. 2003;108(Suppl 1):II180-5.

26. Bauer R, Busch U, van de Flierdt E, Stettmeier H, Raab W, Langhammer HR, et al. Age-related heart function in patients with healthy hearts. Z Kardiol. 1988;77:632-41.

\section{The Journal of Thoracic and Cardiovascular Surgery Conflict of Interest Policy}

To assure fairness to authors submitting work for consideration in The Journal of Thoracic and Cardiovascular Surgery, a mechanism exists for managing conflicts of interest. The editor and each of the section editors complete a "Conflict of Interest" form that identifies any and all relationships with commercial and other academic entities. When the editor has a potential conflict because of a relationship with another entity or author, the editor appoints an alternate editor from among the section editors or editorial board members who assumes the entire responsibility for final decisions on the manuscript in question. The editor does not read the reviews that are submitted nor engage in discussing the manuscript prior to the final decision. When the conflict of interest involves a section editor, a "guest section editor" is appointed who fills the role normally played by the conflicted section editor. All members of the editorial board and reviewers are asked to indicate any conflict of interest when they agree to review a manuscript. 


\section{E-Acknowledgements}

National Heart, Lung, and Blood Institute: Gail Pearson, Tracey Hoke, Carl Hunt, Mario Stylianou, Judith MassicotFisher, Marsha Mathis, Victoria Pemberton

Data Coordinating Center: New England Research Institutes, Lynn Sleeper, Steven Colan, Paul Mitchell, Gloria Klein, Dianne Gallagher, Patty Connell, Lisa Wruck

Network Chair: Lynn Mahony, University of Texas Southwestern Medical Center

Clinical Site Investigators: Children's Hospital Boston, Jane Newburger (PI), Stephen Roth, Roger Breitbart, Renee Margossian, Andrew Powell, Jonathan Rhodes, Jodi Elder, Ellen McGrath; Children's Hospital of New York, Welton M. Gersony (PI), Seema Mital, Beth Printz, Ashwin Prakash, Darlene Servedio; Children's Hospital of Philadelphia, Victoria Vetter (PI), Bernard J. Clark, Mark Fogel, Steven Paridon, Jack Rychik, Margaret Harkins, Jamie Koh; Duke University, Page A. W. Anderson (PI), Rene Herlong, Lynne Hurwitz, Jennifer S. Li, Ann Marie Nawrocki; Medical University of South Carolina, J. Philip Saul (PI), Andrew M. Atz, Andrew D. Blaufox, Girish Shirali, Jon Lucas, Amy
Blevins; Primary Children's Medical Center, Salt Lake City, Utah, LuAnn Minich (PI), Richard Williams, Linda Lambert, Michael Puchalski; Hospital for Sick Children, Toronto, Brian McCrindle (PI), Timothy Bradley, Kevin Roman, Jennifer Russell, Shi-Joon Yoo, Elizabeth Radojewski, Nancy Slater

\section{Core Laboratories}

Cardiac MRI, Children's Hospital Boston: Tal Geva; Andrew J. Powell

Echocardiography, Children's Hospital Boston: Steven Colan (Director), Marcy Schwartz, Renee Margossian

Protocol Review Committee: Michael Artman, Chair; Judith Massicot-Fisher, Executive Secretary; Erle Austin, Daniel Bernstein, Timothy Feltes, Julie Johnson, Jeffrey Krischer, G. Paul Matherne, Anne Murphy, ad hoc, Anne Rowley, ad hoc

Data and Safety Monitoring Board: John Kugler, Chair; Tracey R. Hoke, Executive Secretary; Kathryn Davis, David J. Driscoll, Mark Galantowicz, Sally A. Hunsberger, Thomas J. Knight, Catherine L. Webb, Lawrence Wissow. 